\title{
SUSCEPTIBILITY OF SITOPHILUS ZEAMAIS (MOSTCH.) (COLEOPTERA: CURCULIONIDAE) TO BEAUVERIA BASSIANA AND METARHIZIUM ANISOPLIAE
}

\author{
Addis Teshome ${ }^{1}$ and Tadele Tefera ${ }^{2, *}$ \\ ${ }^{1}$ Ethiopian Institute of Agricultural Research, Bako Research Centre, PO Box 2003, Addis Ababa, Ethiopia \\ ${ }^{2}$ Department of Plant Sciences, College of Agriculture, Haramaya University, PO Box 138, \\ Dire Dawa, Ethiopia. E-mail: tadeletefera@yahoo.com
}

\begin{abstract}
Evaluation of eleven Metarhizium anisopliae and six Beauveria bassiana isolates against the maize weevil Sitophilus zeamais was conducted under laboratory with the objectives of identifying the most virulent locally available fungal isolates, and determining the dose mortality response. The pathogenicity (virulence) of the entomopathogenic fungi was determined using LT $_{50}$ and percent mortality at the conidial concentration of $1 \times 10^{8} \mathrm{ml}^{-1}$. The most virulent isolates of M. anisopliae (PPRC-2, PPRC-14 and PPRC-51) and B. bassiana (PPRC-GG and PPRC-HH) caused $84.4 \%$ to $98.3 \%$ mortality to $S$. zeamais. These isolates had $\mathrm{LT}_{50}$ ranging from 3.8 to 4.3 days. The dose response study with the isolates PPRC-2, PPRC-14 and PPRC-51 at doses ranging from $1 \times 10^{4}$ to $1 \times 10^{8}$ conidia $\mathrm{ml}^{-1}$ revealed susceptibility of the $S$. zeamais with mortality ranging from 25 to $95.5 \%$. There was an increase in the resulting $\mathrm{LT}_{50}$ from 4.0 to 11.9 days with a decrease in conidial concentration from $1 \times 10^{8}$ to $1 \times 10^{4}$ conidia ml- ${ }^{-1}$. PPRC-2 showed the lowest LC50 $(1.46 \times 10$ conidia ml-1) followed by PPRC-14 and PPRC-51 (3.5x 105 and 3.9x 105 conidia $\mathrm{ml}^{-1}$, respectively). In conclusion, the isolates PPRC-2, PPRC-14, PPRC-51, PPRC-GG and PPRC-HH, can be considered as a potential candidates in the development of mycoinsectisdes against $S$. zeamais.
\end{abstract}

Key words/phrases: Beauveria bassiana, Metarhizium anisopliae, mortality, $\mathrm{LC}_{50}, \mathrm{LT}_{50}$

\section{INTRODUCTION}

The maize weevil, Sitophilus zeamais Motsch. (Coleoptera: Curculionidae), is one of the most serious cosmopolitan pest of stored cereal grain, especially of maize (Zea mays L.), in tropical and sub-tropical regions (Throne, 1994). Grain yield losses up to $40 \%$ were reported on stored maize due to S. zeamais in Africa (Meikle et al., 2001). In Africa, where subsistence grain production supports the population, such grain losses may be substantial. In addition to grain weight loss, pests of stored grain also cause secondary fungal infection, resulting in a reduction in seed vigor, quality and commercial value (Meikle et al., 2001).

Synthetic chemical insecticides have been widely used for the control of pests of stored grain, particularly S. zeamais. The widespread use of insecticides for the control of stored-product insect pests is of global concern with respect to environmental hazards, insecticide resistance development, chemical residues in foodstuffs, side effects on non-target organisms and the associated high costs (Cherry et al., 2005). To this effect, the increased public awareness and concern for environmental safety has directed research to the development of alternative control strategies such as the use of entomopathogenic fungi against stored-product insect pests.

Variations in pathogenicity (virulence) among isolates against stored product insects have been previously reported in assays with $B$. bassiana and M. anisopliae on S. zeamais (Adane Kassa et al., 1996; Hildago et al., 1998; Adane Kassa, 2003), Sitophilus oryzae (Dal Bello et al., 2001; Sheeba et al., 2001; Padin et al., 2002), Prostophanus truncatus (Miekel et al., 2001; Adane Kassa, 2003), Sitophilus granarius (Athanassiou and Steenberg, 2006), Rhizopertha domonica (Lord, 2001), Caryedon serratus (Ekesi, 2001), Cryptolestes ferrugeneus (Lord, 2001), Oryzophilus surrinamensis (Thorne and Lord, 2004), Plodia interpunclella and Ephestia kuehniella (Bischoff and Reichmuth, 1997).

One of the first steps in development of an entomopathogenic fungus for the bio-control is selection of virulent strain (Tadele Tefera and Pringle, 2007). Little effort has been made to evaluate the potential of entomopathogeic fungai for biological control of S. zeamais. The objectives of the present study, therefore, were to identify the

\footnotetext{
* Author to whom all correspondence should be addressed.
} 
most virulent locally available fungal isolates of $B$. bassiana and M. anisopliae against the maize weevil S. zeamais and to determine the concentrationmortality response of the most virulent isolates.

\section{MATERIALS AND METHODS}

\section{Rearing S. zeamais}

About 1500 unsexed adult maize weevils collected from the Bako Agricultural Research Centre (BARC), Ethiopia, maize store were placed in 10 four-litre plastic containers each containing $5 \mathrm{~kg}$ of maize. The top of each plastic container was covered with nylon mesh fastened tightly with elastic bands. The insects were allowed for twoweek oviposition periods before all adults were removed. After two weeks of oviposition, all $S$. zeamais were removed and transferred to fresh maize grain in another plastic container. Such removal and transfer of $S$. zeamais to fresh maize grain were repeated for three weeks in order to produce sufficient number of progenies $S$. zeamais of the same batch for the subsequent experiments. Each plastic container where $S$. zeamais oviposited was kept for progeny emergence. Thirty-five days after introduction of weevils in each plastic container, emerging progenies of $S$. zeamais were removed daily until the progenies emergence ceased; and those emerged on the same day were transferred to fresh grain in plastic containers with lids and were kept at the experimental conditions $\left(22 \pm 1^{\circ} \mathrm{C}\right)$ until sufficient number of $S$. zeamais were obtained.

\section{Maize grain}

Insecticide untreated and clean, infestation and dockage free maize grain of variety BH-540 harvested in off-season of 2007 was obtained from the BARC. The initial grain moisture content and seed viability were $12.5 \%$ and $100 \%$, respectively. To avoid risk of secondary infestation grains were stored in deep freeze at $-20^{\circ} \mathrm{C}$ for 21 days before use. It was then kept for two weeks at the experimental conditions for acclimatization of moisture and temperature (Abraham Tadesse, 2003).

\section{Fungal isolates}

A total of seventeen fungal isolates comprising eleven $M$. anisopliae and six B. bassiana were obtained from the Ethiopian Institute of Agricultural Research (EIAR), Plant Protection Research Centre (PPRC), Ambo. The isolates had been isolated from different arthropods in different agro-ecological zones of Ethiopia. However, one isolates, ICIPE-30, was obtained from the International Centre of Insect Physiology and Ecology, Kenya. Details of these isolates are given in Table 1. The initial cultures of all isolates were stored at $4^{\circ} \mathrm{C}$ and sub-culturing was made for the present work.

Table 1. List of Metarhizium anisopliae and Beauveria bassiana isolates tested.

\begin{tabular}{lllll}
\hline Fungal species & Isolate code & Host arthropod & Specific site of origin & Altitude \\
\hline M. anisopliae & PPRC-2 & Pachnoda interrupta & Ashan & 2400 \\
M. anisopliae & PPRC-4 & P. interrupta & Shoa Robit & 1875 \\
M. anisopliae & PPRC-14 & P. interrupta & Dedeaa & 2400 \\
M. anisopliae & PPRC-19 & P. interrupta & Rufe Kure & 1750 \\
M. anisopliae & PPRC-27 & P. interrupta & Dedeaa & 2400 \\
M. anisopliae & PPRC-29 & P. interrupta & Gobenayetu & 2400 \\
M. anisopliae & PPRC-51 & P. interrupta & Shoa Robit & 2400 \\
M. anisopliae & PPRC-56 & P. interrupta & Berber & 1925 \\
M. anisopliae & PPRC-61 & Spider (Arachnida) & Awaketu & 1750 \\
M. anisopliae & PPRC-66 & Spider (Arachnida) & Awaketu & 1950 \\
M. anisopliae & ICIPE-30 & Tse Tse fly & Kenya & Unknown \\
B. bassiana & PPRC-9501 & Chafer grub & Tikur Inchini & 1950 \\
B. bassiana & PPRC-9609 & Blosynus mugulosus & Dila & 2030 \\
B. bassiana & PPRC-9614 & Ground beetle & Awassa & 1500 \\
B. sp. & PPRC-9615 & Spider (Arachnida) & Awassa & 2450 \\
B. bassiana & PPRC-GG & Coleoptera (adult) & Ashange & 2400 \\
B. bassiana & PPRC-HH & Coleoptera (adult) & Ashange & 2400 \\
\hline
\end{tabular}


To produce inocula for experiments, slant cultures of the seventeen isolates from the collections were sub-cultured onto Sabouraud dextrose agar with yeast extract (SDAY) in to a Petri dish sealed with Para film. Cultures were incubated at $27^{\circ} \mathrm{C}$ and $75 \% \mathrm{RH}$ for 20 -days. The surface of 20-day old cultures was scrapped with a sterile scalpel and suspended in aqueous solution of $0.01 \%$ Tween 80 . The fungal suspension was vortexed for one minute to break up the conidial chains or clumps and filtered through several layers of sterile cheesecloth to remove mycelia. The dose of conidia in the filtrate was estimated using heamocytometer under a light microscope (40x magnifications). A standard conidial suspension of $1 \times 10^{8}$ conidia $\mathrm{ml}^{-1}$ was prepared for each isolate.

Viability of conidia was estimated using a dilution plate count method. For each isolate, one $\mathrm{ml}$ of suspension containing $1 \times 10^{4}$ conidia $\mathrm{ml}^{-1}$ were spread plated over SDAY plates with sterile glass rod and sealed with Para film. Four Petri dishes of each fungal isolate were then incubated at $27^{\circ} \mathrm{C}$ and $75 \% \mathrm{RH}$ for $24 \mathrm{hrs}$. Germination rate was determined microscopically for at least 100 conidia from random field views for each isolate. Conidia were considered to have germinated when the germ tube was at least as long as the width of the germ tube. The germination of conidia of the isolates exceeded $80 \%$.

\section{Bioassays}

\section{Single concentration assay}

In this assay seventeen isolates were assayed for pathogenicity against the maize weevil. The weevils were collected from rearing jars, placed in a Petri dish and mixed thoroughly to facilitate random selection of the insects. Laboratory reared 7 to 10 days old adult weevils as described above were used. Fifteen weevils were then introduced to each Petri dish with filter paper inside. For each isolate an aqueous suspension containing $1.0 \times 10^{8}$ conidia $\mathrm{ml}^{-1}$ were prepared in $0.01 \%$ Tween 80 . Inoculation of each batch of weevils was made by directly spraying one $\mathrm{ml}$ of $1.0 \times 10^{8}$ conidia ml-1 of each isolate using a hand held spray atomizer. This conidial concentration was chosen based on our previous report (Tadele Tefera and Prinlgle, 2007). For the control group, the same numbers of maize weevils were treated with sterile distilled water with $0.01 \%$ Tween 80 .

The treated insects and the control were kept in Petri dishes with perforated lid for $24 \mathrm{~h}$ without food at $27^{\circ} \mathrm{C}$ and $70 \pm 5 \% \mathrm{RH}$. This was done to avoid dislodging of conidia by the maize kernels. After $24 \mathrm{~h}$, insects were transferred to glass jar (250 $\mathrm{ml}$ capacity) containing $200 \mathrm{~g}$ of cracked and disinfected maize kernels and the jars were covered with a perforated lid. The treatments were maintained at $27^{\circ} \mathrm{C}$ and $70 \pm 5 \% \mathrm{RH}$ for 10 days. All the treatments and the controls were replicated four times in a completely randomized design.

Mortality was recorded daily for ten days. An observation of each jar was done by emptying the contents of each jar onto white paper to identify dead individuals. The dead adults collected were immediately submerged in to $95 \%$ ethanol for one minute and washed in sterile distilled water for five minutes to remove saprophytes and all conidia found on the outer surface of the insect body. The disinfected cadavers were then allowed to dry for ten minutes. This step was added to ensure that mycosis observed on the surface of the cadavers would not be attributed to spores used during the treatment but rather to growth from the interior to the exterior of the insect after colonization of internal organs. Cadavers were then held under high humidity on Petri dishes containing damp filter paper to provide sufficient humid conditions to promote fungal outgrowth. Petri dishes were sealed with Para film to maintain greater than $95 \%$ $\mathrm{RH}$ and were incubated in the dark at $27^{\circ} \mathrm{C}$. Insects were considered mycosed when growth of the fungus was visible on the external surface of the insect's cuticle and those which showed hyphal growth characteristic of the entomopathogenic fungi were recorded as infected.

\section{Multiple concentration assays}

The dose responses of the isolates PPRC-2, PPRC-51 and PPRC-14 were determined. The isolates were selected based on the results of single dose assay in which they caused at least 95\% mortality (Table 2). Serial dilutions were made to obtain five different conidial doses $\left(1 \times 10^{4}, 1 \times 10^{5}, 1 \times 10^{6}, 1 \times 10^{7}\right.$ and 1 $x 10^{8}$ conidia $\mathrm{ml}^{-1}$ ) with $0.01 \%$ Tween 80 . The conidial suspensions were applied to weevils following the same procedure as described above. Fifteen newly emerged adult maize weevils were used for each dose of each isolate. The control group was treated with sterile distilled water containing $0.01 \%$ Tween 80 . Petri dishes containing treated and control insects were sealed with Para film and incubated at $27^{\circ} \mathrm{C}$. The treated insects and the controls were provided with untreated cracked maize grains 24 hours after treatment application. All treatments and the controls were replicated four times and arranged in a completely randomized design. Insect mortality was recorded daily for ten days. Dead insects were removed and placed in a Petri dish with moist filter paper. Fungal infection was confirmed after observing sporulated cadavers under stereomicroscope. 
Table 2.. Mean $\mathrm{LT}_{50}$ of $S$. zeamais 10 days after treatment with the isolates of $M$. anisopliae and B. bassiana at the rate of $1 \times 10^{8}$ conidia $\mathrm{ml}^{-1}$.

\begin{tabular}{llccccc}
\hline Fungal species & Isolate code & LT $_{50}$ (days) & $95 \%$ CI & Slope \pm S.E & Chi-square & P-value \\
\hline M. anisopliae & PPRC-2 & $3.9 \pm 0.723$ & $1.5-5.33$ & $0.77 \pm 0.055$ & 7968.5 & $<0.001$ \\
M. anisopliae & PPRC-4 & $10.2 \pm 0.361$ & $8.3-15.03$ & $0.20 \pm 0.2$ & 31.54 & $<0.001$ \\
M. anisopliae & PPRC-14 & $4.2 \pm 0.61$ & $3.3-5.02$ & $0.65 \pm 0.44$ & 494.48 & $<0.001$ \\
M. anisopliae & PPRC-19 & $9.6 \pm 0.353$ & $8.6-11.43$ & $0.22 \pm 0.024$ & 23.3 & 0.003 \\
M. anisopliae & PPRC-27 & $23.6 \pm 0.347$ & $16-52.6$ & $0.17 \pm 0.03$ & 7.47 & 0.49 \\
M. anisopliae & PPRC-29 & $15.6 \pm 0.401$ & $12.4-23.6$ & $0.21 \pm 0.29$ & 8.13 & 0.42 \\
M. anisopliae & PPRC-51 & $4.3 \pm 0.522$ & $3.5-45.1$ & $0.57 \pm 0.04$ & 189.3 & $<0.001$ \\
M. anisopliae & PPRC-56 & $6.6 \pm 0.44$ & $6.3-7.03$ & $0.36 \pm 0.027$ & 27.2 & 0.001 \\
M. anisopliae & PPRC-61 & $16.5 \pm 0.64$ & $12.9-27.6$ & $0.22 \pm 0.04$ & 12.6 & 0.122 \\
M. anisopliae & PPRC-66 & $10.2 \pm 0.347$ & $8.3-14.9$ & $0.21 \pm 0.02$ & 29.2 & $<0.001$ \\
M. anisopliae & ICIPE-30 & $7.8 \pm 0.398$ & $6.9-9.26$ & $0.28 \pm 0.025$ & 34.9 & $<0.001$ \\
B. bassiana & PPRC-9501 & $7.9 \pm 0.345$ & $6.5-9.373$ & $0.25 \pm 0.02$ & 38.63 & $<0.001$ \\
B. bassiana & PPRC-9609 & $17.8 \pm 0.668$ & $13.6-32.55$ & $0.22 \pm 0.34$ & 2.62 & 0.956 \\
B. bassiana & PPRC-9614 & $30.9 \pm 0.504$ & $18.5-139.6$ & $0.17 \pm 0.038$ & 2.2 & 0.974 \\
B. bassiana & PPRC-9615 & $22.5 \pm 0.368$ & $15.6-48.13$ & $0.16 \pm 0.027$ & 7.16 & 0.519 \\
B. bassiana & PPRC-GG & $4.0 \pm 0.282$ & $3.8-5.56$ & $0.33 \pm 0.24$ & 73 & $<0.001$ \\
B. bassiana & PPRC-HH & $4.2 \pm 0.44$ & $3.3-5.03$ & $0.50 \pm 0.32$ & 154.5 & $<0.001$ \\
\hline
\end{tabular}

$\mathrm{CI}=$ Confidence interval $; \mathrm{SE}=$ Standard error .

\section{Statistical analysis}

Mortality data were corrected for the control mortality $\% C M=\frac{(\% T-\% C)}{(100-\% C)} * 100$; where $\mathrm{CM}$ is corrected mortality, $\mathrm{T}$ is mortality in treated insects and $\mathrm{C}$ is mortality in untreated insects (Abbott, 1925). The data were arcsine transformed to stabilize variances. Mortality was analyzed using one-way analysis of variance (ANOVA) $(\mathrm{P}<0.001)$ with PROC ANOVA (SAS Institute, 1999). Least significance difference (LSD) test was used to separate means. The LT50 (Lethal time required to kill $50 \%$ of the treated insect population) was determined using probit analysis.

Mortality was corrected for the control (Abbott, 1925). LC50 (Lethal dose of conidia required to kill $50 \%$ of the treated insect population) was determined using probit analysis. An arcsine transformation of percentage mortality was performed. Mortality data were analyzed using General Linear Model's Procedure (PROC GLM). Least significance difference (LSD) test was used to separate means (SAS Institute, 1999).

\section{RESULTS}

\section{Single concentration assay}

No mortality observed in control insects. There were significant differences $(\mathrm{F}=13.923, \mathrm{df}=17, \mathrm{P}<$
0.001) between fungal treatments in causing mortality to S. zeamais (Fig. 1). The isolates PPRC9614, PPRC-9609, PPRC-27, PPRC-29, PPRC-61, and PPRC-9615, were the least virulent causing mortality, $13.3 \%$ to $31.7 \%$, whilst the isolates PPRC4, PPRC-19, PPRC-56, ICIPE-30 and PPRC-66, were moderate in virulence inducing $40 \%$ to $73 \%$ mortality. However, PPRC-2, PPRC-51, PPRC-14, PPRCGG and PPRC-HH were the most virulent isolates with $84.8 \%$ to $98.32 \%$ mortality (Fig. 1).

Though all isolates induced mortality, the single dose time-mortality assay demonstrated important differences in $\mathrm{LT}_{50}$ values between the isolates (Table 2). The mortality rate of the three groups of the isolates was highly related to $\mathrm{LT}_{50}$. The isolates which had the least $\mathrm{LT}_{50}$ values, had the highest mortality rates and vice versa. The $\mathrm{LT}_{50}$ ranged from 3.8 to 30.9 days. The most virulent, moderately and weakly virulent isolates had LT50 ranging from 3.8 to $4.3,6.6$ to 10.2 and 16.5 to 30.9 days, respectively. The slopes of the lines are different $(P<0.05)$ from zero except for the isolates PPRC-27, PPRC-29, PPRC-61，PPRC-9609， PPRC-9614 and PPRC-9615.

\section{Multiple concentration assays}

The LC50 of PPRC-2 $\left(1.4 \times 10^{5}\right.$ conidia $\left.\mathrm{ml}^{-1}\right)$ was lower than that of PPRC-51 $\left(3.9 \times 10^{5}\right.$ conidia $\left.\mathrm{ml}^{-1}\right)$ and PPRC-14 (3.5 x105 conidia $\left.\mathrm{ml}^{-1}\right)$ (Table 3). However, there was an overlap in fiducial limits 
between the isolates. Therefore, the differences in the $\mathrm{LC}_{50}$ values were not significant.

There were also significant differences $(\mathrm{F}=163.6$, $\mathrm{df}=2, \mathrm{P}<0.01)$ between isolates in mortality $(\mathrm{F}=$ 6.04, $\mathrm{df}=4 \mathrm{P}<0.01$ ) (Table 4). No mortality was observed in control insects. The cumulative mortality of all isolates at different rates indicated the dose dependent mortality of $S$. zeamais. The $S$. zeamais mortality at the highest $\left(1 \times 10^{8}{\left.\text { conidia } \mathrm{ml}^{-1}\right)}^{-1}\right.$ and lowest $\left(1 \times 10^{4}\right.$ conidia ml $\left.^{-1}\right)$ conidial concentration ranged from $93 \%$ to $95 \%$ and $25 \%$ to $28.33 \%$, respectively (Table 4). At the three higher concentrations (dosages), PPRC-2 caused significantly higher mortality than the other isolates. At low application concentration $\left(1 \times 10^{4}\right.$ and $1 \times 10^{5}$ conidia $\left.\mathrm{ml}^{-1}\right)$, the mortality level was significantly decreased. There was an increase in LT50 with a corresponding decrease in conidial concentration. The LT50 value ranged from 4.2 to 4.6 days and 11.7 to 11.8 days for the highest and the lowest conidia concentration, respectively.

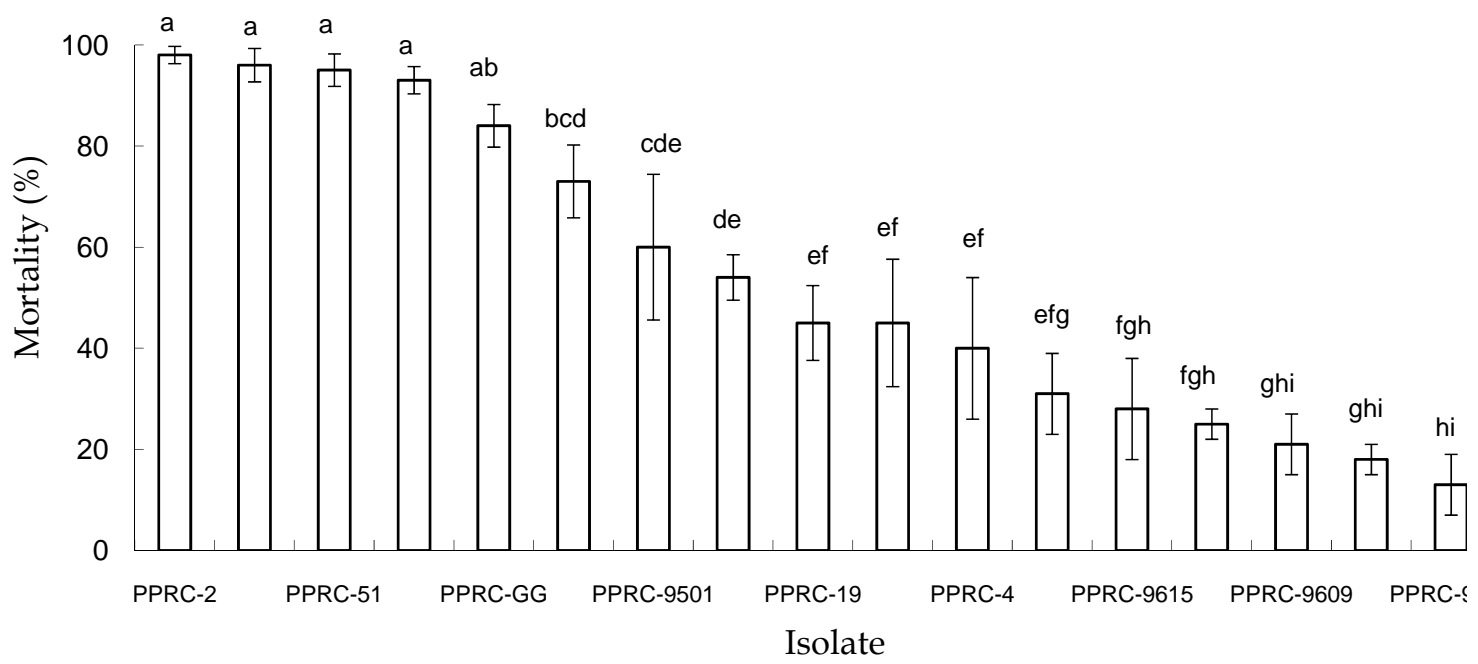

Fig. 1. Mean percentage mortality $( \pm \mathrm{SE})$ of $S$. zeamais 10 days after treatment with the isolates of $M$. anisopliae and B. bassiana at the rate of $1 \times 10^{8}$ conidia $\mathrm{ml}^{-1}$.

Table 3. $\mathrm{LC}_{50}$ of three isolates of M. anisopliae against S. zeamais.

\begin{tabular}{lllll}
\hline Fungal isolates & LC50 & $95 \%$ Fiducial limit & Slope $(\mathrm{SE})$ & $\mathrm{X}^{2}(\mathrm{df}=3)$ \\
\hline PPRC-2 & $1.46 \times 10^{5}$ & $6.4 \times 10^{4}-2.8 \times 10^{5}$ & 0.064 & 4.33 \\
PPRC-14 & $3.5 \times 10^{5}$ & $1.7 \times 10^{5}-8.3 \times 10^{5}$ & 0.063 & 3.35 \\
PPRC-51 & $3.9 \times 10^{5}$ & $1.7 \times 10^{5}-6.8 \times 10^{5}$ & 0.059 & 4.19 \\
\hline
\end{tabular}

Table 4. Mortality and $\mathrm{LT}_{50}$ of $S$. zeamais six days after treatment with different conidial concentration of $M$. anisopliae.

\begin{tabular}{|c|c|c|c|c|c|c|}
\hline \multirow{2}{*}{ Conidial Conc. ml-1 } & \multicolumn{3}{|c|}{ Mortality $( \pm \mathrm{SE})^{*}$} & \multicolumn{3}{|c|}{$\mathrm{LT}_{50}$ (days) } \\
\hline & PPRC-2 & PPRC-14 & PPRC-51 & PPRC-2 & $\begin{array}{l}\text { PPRC-14 } \\
\end{array}$ & PPRC-51 \\
\hline $1 \times 10^{4}$ & $28.3 \pm 4.9 \mathrm{e}$ & $25.0 \pm 3.19 \mathrm{e}$ & $26.6 \pm 4.7 \mathrm{e}$ & 11.7 & 11.9 & 11.8 \\
\hline $1 \times 10^{5}$ & $38.3 \pm 3.1^{\mathrm{d}}$ & $30.0 \pm 1.92 \mathrm{~d}$ & $38.3 \pm 3.19 \mathrm{~d}$ & 9.6 & 10.9 & 9.6 \\
\hline $1 \times 10^{6}$ & $76.6 \pm 4.3^{c}$ & $61.6 \pm 6.3^{c}$ & $51.6 \pm 1.67 \mathrm{c}$ & 5.9 & 6.9 & 7.9 \\
\hline $1 \times 10^{7}$ & $81.6 \pm 3.19^{b}$ & $76.6 \pm 4.3^{b}$ & $70.0 \pm 4.3^{b}$ & 5.5 & 5.9 & 5.5 \\
\hline $1 \times 10^{8}$ & $95.0 \pm 3.19 a$ & $93.3 \pm 2.7 \mathrm{a}$ & $93.3 \pm 2.7^{a}$ & 4.2 & 4.8 & 4.6 \\
\hline
\end{tabular}

*Mean values followed by the same letter within a row are not significantly different $(\mathrm{P}<0.05)$ using the least significance difference (LSD) test. 


\section{DISCUSSION}

The presented study demonstrated variation in pathogenicity among the fungal isolates. The cause for such variation in pathogenicity possibly attributed to production of toxic substances by the isolates, immune system of the host and the bioassay temperature. Adane Kassa et al. (1996) and Tadele Tefera (2004) reported that the pathogenicity of some of these isolates was affected when the temperature was below $25^{\circ} \mathrm{C}$. Development of fungal pathogen within hosts can be influenced not only by immune reaction of the host but also indirectly by the hosts' diet (Tadele Tefera and Pringle, 2003; Moorehouse et al., 1993). The difference in the ability of an isolate to overcome the host defence system may be reflected in the increased insect survival following treatment as well as the higher $\mathrm{LT}_{50}$. The differences observed in $\mathrm{LT}_{50}$ values in isolates tested here could reflect genetic and physiological differences between isolates or factors such as toxins or characteristics of the insect host. Moorehouse et al. (1993) demonstrated that $\mathrm{LT}_{50}$ was correlated with spore dose and it is, therefore, only possible to compare directly the result of different bioassay systems if the dose received by individual insects is known.

Moino et al. (1998) and Dal Bello et al. (2006) reported greater mortality of stored grain pests inoculated with Beauveria isolates than Metarhizium isolates. In contrast to these findings, the present study clearly demonstrated that when either B. bassiana or M. anisopliae were applied to $S$. zeamais, the later caused higher mortality and shorter median survival time. For instance, $M$. anisopliae isolates (PPRC-2, PPRC-14 and PPRC-51) caused higher mortality than $B$. bassiana isolates (PPRC-HH and PPRC-GG). The differences are might be attributed to the virulence of the isolated tested.

The study indicated that the isolates were not specific to their original host as none of the isolates tested were from S. zeamais. Todrova et al. (2002) also indicated that the original host was not found to be a reliable indicator of the pathogenicity of a specific fungus to a specific host. Tadele Tefera (2004) also reported high pathogenicity of the isolates PPRC-4 and PPRC-HH to the spotted stem borer Chilo partellus. However, Talaei-Hassanloui et al. (2006) stated that the most virulent isolates to a host are those that are isolated from the same or related host species. It is agreed that $B$. bassiana and M. anisopliae have wide host ranges and their pathogenicity also vary according to their host. There is increasing evidence that habitat selection drives the pathogenicity of $B$. bassiana and $M$. anisopliae (Bidochka et al., 2000). Thus, results from this study indicate that screening of potential isolates should not be limited to those isolated from the original host.

The isolate PPRC-2 was consistently more virulent than PPRC-14 and PPRC-51. Thus, considering both the $\mathrm{LT}_{50}$ and $\mathrm{LC}_{50}$ values, these isolates may be considered among the most virulent isolates tested against adult maize weevils in this study. The observed high mortality at $1 \times 10^{8}$ and $1 \times 10^{7}$ conidia $\mathrm{ml}^{-1}$ seem to be attributable to the increased number of conidia that adhered to an insect at these doses. Mortality occurred at all doses for all isolates but to a limited (25\% to $28 \%$ mortality) extent at low doses. This low mortality appeared to stem from the slow development of infection at lower dose (Yoon et al., 1999). Large doses containing the host causes death in few days, whereas, low doses may take two or more weeks to kill (Hidalgo et al., 1998). Adane Kassa et al. (1996) evaluated the pathogenicity of ten $B$. bassiana isolates to the maize weevil and found that one of the isolates caused $88 \%$ mortality within eight days at $1 \times 10^{4}$ conidia $\mathrm{ml}^{-1}$ indicating very virulent isolates could cause high mortality at lower doses. High dose requirement for stored grain pests has been reported for $T$. castaneum (Padin et al., 2002) and Cheryy et al. (2005) on Callosobruchus maculatus. However, even at lower doses, $B$. bassiana has shown to have a comparatively better performance on $R$. dominica, $O$. surinamensis and Cryptolestes ferrugineus (Lord, 2001). Adane Kassa (2003) also reported that $B$. bassiana isolates appeared virulent to $S$. zeamais only at doses higher than $1 \times 10^{7}$ conidia $\mathrm{ml}^{-1}$ and variability within the different $B$. bassiana isolates was apparent.

The result also suggests virulence of the entomopathogenic fungi is not always related to the original host or place of origin as none of the isolates tested are from the test insect based on the present study. The isolates PPRC-2, PPRC-14, PPRC51, PPRC-GG and PPRC-HH, can be recommended as primary candidates for further research work in 
order to develop a mycoinsecticide against $S$. zeamais.

\section{ACKNOWLEDGEMENTS}

The Ethiopian Institute of Agricultural Research, Bako Research Centre, is acknowledged for sponsoring this study.

\section{REFERENCES}

1. Abbott, W.S. (1925). A method of computing the effectiveness of an insecticide. Journal of Economic Entomology 18:265-267.

2. Abraham Tadesse (2003). Studies on some nonchemical insect pest management options on farm-stored maize in Ethiopia. A PhD Dissertation, Giessen University, Germany. 246 pp.

3. Adane Kassa, Moore, D. and Archer, S.A. (1996). Preliminary studies on the use of Beauveria bassiana to control Sitophilus zeamais (Coleoptera: Curculionidae) in the laboratory. Journal of Stored Products Research 32:105-113.

4. Adane Kassa (2003). Development and testing of mycoinsecticides based on submerged spores and aerial conidia of the entomopathogenic fungi Beauveria bassiana and Meterhazium anisopliae (Deutromycotina: hyphomycetes) for control of locusts, grasshoppers and storage pest. A $\mathrm{PhD}$ Dissertaion, Georg-AugustUnivesity Gottingen, Germany. 170 pp.

5. Athanassiou, C.G. and Steenberg, T. (2006). Insecticidal effect of Beauveria bassiana (Balsamo) Vuillemin (Ascomycota: Hypocreaes) in combination with three diatomaceous earth formulations against Sitophilus granarius (L.) (Coleoptera: Curculionidae). Biological Control 40:411-416. 6. Bidochka, M.J., Kamp, A.M. and De Croos, J.N.A. (2000). Fungal Pathology. In: Insect Pathogenic Fungi: from Genes to Populations, pp. 171-193, (Kronstad, J.W., ed.), Kluver Academic Press, The Netherlands.

7. Bischoff, R. and Reichmuth, R. (1997). Pathogenicity factors of entomopathogenic fungi of Plodia interpunctella (Hubner) and Ephestia Kueniella (zeller) (Lepidoptera: Pyralidae). In: Proceedings of the International Conference on Pests on Agriculture, 6-8 January, 1977 at Le corum, Montpellier, France, Vol. 3. ANPP, Paris, France.

8. Cherry, A. J., Bantino, A., Djegui, D. and Lomers, C. (2005). Suppression of the stem borer Sesamia calamistis (Lepidoptera: Noctuidae) in maize following seed dressing, topical application, and stem injection with African isolates of Beauveria bassiana. International Journal of Pest Management 50: 67-73.

9. Dal Bello, G., Padin, C., Lopez, L. and Fabrizio, M. (2001). Laboratory evaluation of chemicalbiological control of the rice weevil (Sitophilus oryzae L.) in stored grain. Journal of Stored Products Research 37:77-84.

10. Dal Bello, G., Padin, S., Juarez, P. and Pedrini, N.B. (2006). Biocontrol of Acanthoscelides obtectus and Sitophilus oryzae with Diatomaceous Earth and Beauveria bassiana on stored grain. Biocontrol Science and Technology 16:215-220.

11. Ekesi, S. (2001). Pathogenicity and antifeedant activity of entomopathogenic hyphmycetes to the cowpea leaf beetle, Ootheca mutabilis shalberg. Insect Science and its Application 21: 55-60.

12. Hidalgo, E., Moore, D. and Le Patourel, G. (1998). The effect of different formulations of Beauveria bassiana on Sitophilus zeamais in stored maize. Journal of Stored Products Research 34:171-179.

13. Lord, J. C. (2001). Desiccant dusts synergies the effect of Beauveria bassiana (Hyphomycetes: Moniliales) on stored grain beetles. Journal of Economic Entomology 94:367-372.

14. Miekel, W.G., Cherry, A.J., Holst, N.B., Hounna, B. and Markham, R.H. (2001). The effect of an entomopathogenic fungus Beauveria bassiana on Prostophanus trancatus (Horn) (Col: Bostrichidae), Sitophilus zeamais Motschulsky (Col: Cuculionidae) and grain losses in stored maize in the Benin Republic. Journal of Invertebrate Pathology 77:198-205.

15. Moino, J., Alves, A.S.B. and Periera, R.M. (1998). Efficacy of Beauveria bassiana (Balsamo) Vuillemin isolates for control of stored grain pests. Journal of Applied Entomology 122:301-305.

16. Moorhouse, E.R., Gillespie, A.J. and Charnley, A.K. (1993). Laboratory selection of Metarhizium spp. isolates for control of vine weevil larvae (Otiorhynchus sulcatus). Journal of Invertebrate Pathology 62:15-21.

17. Padin, S., Dal Bello, G. and Fabrizio, M. (2002). Grain losses caused by Tribolium castaneum, Sitophilus oryzae and Acanthoscelides obtectus in stored durum wheat and beans treated with Beauveria bassiana. Journal of Economic Entomology 38:6974 .

18. SAS Institute (1999). The SAS Statstical System, Version 8. SAS Institute, Carry, NC.

19. Sheeba, G., Seshardi, S., Raja, N., Janathanan, S. and Ignacimuthu, S. (2001). Efficacy of B. bassiana for control of the rice weevil, S. oryzae (L.) (Coleoptera: Curculionidae). Applied Entomology and Zoology 36:117-120. 
20. Tadele Tefera (2004). Evaluation of the entomopathogenic fungi Beauveria bassiana and Metarhizium anisopliae for biological control of the spotted stem borer, Chilo partellus (Swinhoe) (Lepidoptera: Crambidae). A PhD Dissertation, University of Stellenbosch, South Africa, 127 pp.

21. Tadele Tefera and Pringle, K.L. (2003). Food consumption by Chilo partellus (Lepidoptera: Pyralidae) larvae infected by Beauveria bassiana and Metarhizium anisopliae and effect natural versus artificial diet on mortality and mycosis. Journal of Invertebrate Pathology 84:220-225.

22. Tadele Tefera and Pringle, K.L. (2007). Biological control of the spotted stem borer Chilo partellus (Swinhoe) (Lepidoptera: Crambidae) with the entomopathogenic fungi, Beauveria bassiana and Metarhizium anisopliae. SINET. Ethiopian Journal of Science 30: 65-70.

23. Talaei-Hassanluoi, R., Kharazi-Pakdel, A., Goettel, M. and Mozaffari, J. (2006). Germination polarity of Beauveria bassiana and its possible correlation with pathogenicity. Journal of Invertebrate Pathology 94:102-107.
24. Throne, J.E. (1994). Life history of immature maize weevils (Coleoptera: Curculionidae) on corn stored at constant temperatures and relative humidities in the laboratory. Environmental Entomology 23:1459-1471.

25. Thorne, J.E. and Lord, J.C. (2004). Control of sawtoothed grain beetles (Coleoptera:Silvinidae) in stored oats by using entomopathogenic fungus in conjunction with seed resistance. Journal of Economic Entomology 97:1765-1771.

26. Todorova, S. I., Cloutier, C., Cote, J.C. and Corderre, O. (2002). Pathogenicity of six isolates of Beauveria bassiana (Balsmo) Vuillemin (Deutromycotina: Hyphomycetes) to Perillus bioculatus (F.) (Hem: pentatomidae). Journal of Applied Entomology 126:182-185.

27. Yoon, C.S., Sung, G.H., Park, H.S., Lee, S.G. and Lee, J.O. (1999). Potential of the entomopathogenic fungus, Beauveria bassiana strain CS-1 as a biological control agent of Plutella xylostella (Lepidoptra: Yponomeutidae). Journal of Applied Entomology 123:423-425. 